\title{
ANÁLISE DE UMA SEQUÊNCIA DIDÁTICA NO ENSINO DO SISTEMA CARDIOVASCULAR
}

\author{
Maria Rozeleide de Oliveira Nóbregal \\ Fabrício Bonfim Sudério²
}

\section{RESUMO}

O ensino de Biologia tem encontrado dificuldades para cumprir o seu objetivo de levar os estudantes a aprender de forma satisfatória, sobretudo em relação a alguns conteúdos considerados mais complexos. No sentido de superar essa problemática, algumas práticas pedagógicas podem ser efetivas, como o uso de sequências didáticas. O objetivo desta pesquisa foi avaliar a eficácia de uma sequência didática com metodologia prática e lúdica como facilitadora do ensino e da aprendizagem da anatomia e fisiologia do sistema cardiovascular. A abordagem foi qualitativa e consistiu na aplicação de uma sequência didática como forma de mediar o processo de ensino aprendizagem. A coleta dos dados baseou-se em observações sistemáticas, além de aplicação e análise de questionários semiestruturados. A pesquisa fora realizada com 44 estudantes de uma escola profissionalizante da rede pública estadual da cidade de Tauá, Ceará. A sequência didática foi estruturada em três momentos pedagógicos, utilizando-se de estratégias metodológicas variadas, como jogo, animações e atividades práticas. A análise dos dados revelou que a metodologia proporcionou um ganho expressivo no aprendizado do conteúdo abordado, favorecendo o envolvimento, a participação e o interesse nas aulas. Pôde-se concluir que a sequência didática apresentou grande potencial como facilitadora da aprendizagem, sendo confirmada a sua eficácia na abordagem do ensino de anatomia e fisiologia do sistema cardiovascular.

Palavras-chave: Ensino de biologia. Aprendizagem interativa. Ensino e pesquisa.

\section{ANALYSIS OF A DIDACTIC SEQUENCE IN TEACHING THE CARDIOVASCULAR SYSTEM}

\section{ABSTRACT}

\footnotetext{
1 Mestra em Ensino de Biologia. Universidade Estadual do Ceará (UECE), Fortaleza, Ceará, Brasil. Orcid iD: https://orcid.org/0000-0003-3668-884X. E-mail: rozeleideoliveiranobrega@gmail.com

2 Doutor em Bioquímica. Professor da Universidade Estadual do Ceará (UECE), Fortaleza, Ceará, Brasil. Orcid iD: https://orcid.org/0000-0001-5937-5681. E-mail:

fabricio.suderio@vece.br
} 
The teaching of Biology has found it difficult to fulfill its objective of taking students to learn satisfactorily, especially in relation to some content considered more complex. In order to overcome this problem, some pedagogical practices can be effective, such as the use of didactic sequences. The objective of this research was to evaluate the effectiveness of a didactic sequence with practical and playful methodology as a facilitator of teaching and learning the anatomy and physiology of the cardiovascular system. The approach was qualitative and consisted of applying a didactic sequence as a way to mediate the teaching-learning process. Data collection was based on systematic observations, in addition to the application and analysis of semi-structured questionnaires. The research was carried out with 44 students from a vocational school in the state public school in the city of Tauá, Ceará. The didactic sequence was structured in three pedagogical moments, using varied methodological strategies, such as games, animations and practical activities. The analysis of the data revealed that the methodology provided an expressive gain in the learning of the approached content, favoring the involvement, the participation and the interest in the classes. It was possible to conclude that the didactic sequence presented great potential as a facilitator of learning, being confirmed its effectiveness in approaching the teaching of anatomy and physiology of the cardiovascular system.

Keywords: Biology teaching. Interactive learning. Teaching and research.

\section{ANÁLISIS DE UNA SECUENCIA DIDÁCTICA EN LA ENSEÑANZA DEL SISTEMA CARDIOVASCULAR}

\section{RESUMEN}

La enseñanza de la biología ha tenido dificultades para cumplir su objetivo de llevar a los estudiantes a aprender satisfactoriamente, especialmente en relación con algunos contenidos considerados más complejos. Para superar este problema, algunas prácticas pedagógicas pueden ser efectivas, como el uso de secuencias didácticas. El objetivo de esta investigación fue evaluar la efectividad de una secuencia didáctica con metodología práctica y lúdica como facilitador de la enseñanza y el aprendizaje de la anatomía y fisiología del sistema cardiovascular. El enfoque fue cualitativo y consistió en aplicar una secuencia didáctica como una forma de mediar en el proceso de enseñanza-aprendizaje. La recopilación de datos se basó en observaciones sistemáticas, además de la aplicación y el análisis de cuestionarios semiestructurados. La investigación se llevó a cabo con 44 estudiantes de una escuela vocacional en la escuela pública estatal de la ciudad de Tauá, Ceará. La secuencia didáctica se estructuró en tres momentos pedagógicos, utilizando estrategias metodológicas variadas, como juegos, animaciones y actividades prácticas. El análisis de los datos reveló que la metodología proporcionó una ganancia expresiva en el aprendizaje del contenido abordado, favoreciendo su desarrollo, la participación y el interés en las clases. Se pudo concluir que la secuencia didáctica presentaba una gran potencial como facilitadora del aprendizaje, confirmando su efectividad para abordar la enseñanza de la anatomía y la fisiología del sistema cardiovascular. 
Palabras clave: Enseñanza de biología. Aprendizaje interactivo. Docencia e investigación.

\section{INTRODUÇÃO}

A ideia de formar cidadãos críticos, participativos, ativos e com competências e habilidades para a construção de seu próprio aprendizado, tão difundida pelos documentos norteadores da educação em nosso país, ainda parece estar bem distante da realidade. Especificamente no ensino de Biologia, continuamos a presenciar aulas descontextualizadas que privilegiam exposições teóricas basicamente embasadas pelos livros didáticos (LIMA; TEIXEIRA, 2011 ).

De acordo com Pedreira, Carneiro e Silva (2011), o livro didático é o principal instrumento utilizado pelos professores que orientam o conteúdo a ser administrado, a sua sequência e as atividades avaliativas no ensino de ciências. Embora se compreenda a importância do livro didático como recurso na sala de aula, é importante que sua utilização se dê de forma crítica e que este não seja a única fonte de conhecimento a ser utilizada pelo professor.

Sant'anna (2017) reforça que é preciso buscar novas possibilidades para que a aprendizagem se efetive, pois se houver um planejamento das aulas com diferentes estilos metodológicos é possível atrair a atenção de um número maior de alunos e alcançar resultados satisfatórios de aprendizagem. Nesta busca, é necessário que os professores procurem acompanhar as novidades das pesquisas nessa área.

É importante atentar para alguns conteúdos que se destacam por apresentar um maior nível de dificuldade para serem aprendidos. Dentre esses, o estudo de anatomia e fisiologia é considerado complexo devido à difícil nomenclatura das estruturas aliada à complexidade de eventos e reações que envolvem esse tema (ALVES et al., 2016; BARBOSA; RAMOS SEREIA, 2010; CANEPPA et al., 2015; JESUS, 2014; WILLERS et al., 2013).

Lima, Siqueira e Costa (2013) afirmam que o emprego de metodologias que despertem a atenção e o interesse dos alunos para os 
assuntos abordados pode promover maior motivação para aprender. Neste sentido, a utilização de metodologias lúdicas e práticas de ensino pode facilitar esse processo, já que prioriza a participação ativa do aluno no processo de ensino-aprendizagem.

Todos esses aspectos podem ser integrados e organizados por meio de uma Sequência Didática (SD). Alencar et al. (2015) ressaltam que a SD é considerada um instrumento fundamental que facilita a abordagem de conceitos de difícil compreensão, sendo uma estratégia importante para o processo de ensino-aprendizagem.

A importância de uma sequência didática reside no encadeamento lógico e coerente de atividades, de acordo com um nível hierárquico de complexidade pensado para atingir objetivos de aprendizagem e uma compreensão cada vez mais aprofundada dos conteúdos. Na sequência didática, os conhecimentos científicos devem ser problematizados em poucas aulas, devendo levar o aluno ao estudo e à discussão de um tema de maneira mais aprofundada (BASTOS et al., 2017). É necessário que a sequência inclua atividades práticas e lúdicas que favoreçam a construção de conhecimentos pelos estudantes e que o conhecimento prévio destes seja levado em consideração (BASTOS et al., 2017; PERETTI; TONIN DA COSTA, 2013).

Considerando os aspectos expostos, o objetivo geral deste trabalho foi avaliar a eficácia de uma SD com metodologia prática e lúdica como facilitadora do ensino e da aprendizagem da anatomia e fisiologia do Sistema Cardiovascular (SC). Os objetivos específicos foram: Identificar os conhecimentos prévios e posteriores dos alunos sobre anatomia e fisiologia do sistema cardiovascular; Verificar a influência de jogos, animações e atividades práticas como facilitadores da aprendizagem; e Analisar o desempenho dos estudantes nas atividades propostas pela sequência didática.

\section{METODOLOGIA}

Revista Exitus, Santarém/PA, Vol. 10, p. 01-31, e020099, 2020. 
A abordagem utilizada nesta pesquisa é a qualitativa e o método adotado para a realização desse trabalho foi a pesquisa-ação, descrito por Felcher, Ferreira e Folmer (2017) como um método que possibilita ao professor construir os conhecimentos, aperfeiçoar a sua prática e contribuir para a melhoria dos resultados de aprendizagem.

A pesquisa foi realizada em uma escola profissionalizante de nível médio da rede pública estadual do Ceará, localizada no município de Tauá. Os sujeitos da pesquisa foram 44 (quarenta e quatro) estudantes do $2^{\circ}$ ano do curso técnico de enfermagem, mediante autorização por meio de um termo de assentimento a estudantes menores de 18 anos. Essa investigação segue os regulamentos propostos pelo Conselho Nacional de Saúde (CNS) 510/2016, sendo a proposta aprovada pelo Comitê de Ética em Pesquisa com Seres Humanos da Universidade Estadual do Ceará (UECE).

A pesquisa consistiu na aplicação de uma sequência didática como forma de mediar o processo de ensino-aprendizagem de anatomia e fisiologia do sistema cardiovascular humano, envolvendo técnicas de coleta de dados padronizadas com base em observações sistemáticas, além de aplicação e análise de questionários semiestruturados.

Inicialmente foi aplicado um questionário pré-teste contendo 15 (quinze) questões objetivas para o levantamento de conhecimentos prévios sobre anatomia e fisiologia do sistema cardiovascular. Os alunos envolvidos na pesquisa tiveram o anonimato resguardado e foram identificados pela letra "A" seguida de números, como: "Al", "A2", "A3", e assim sucessivamente.

Após a realização da sequência didática fez-se a aplicação e a análise de um questionário pós-teste contendo as mesmas 15 (quinze) questões objetivas sobre anatomia e fisiologia cardiovascular aplicadas no pré-teste.

A sequência didática desenvolvida em $10 \mathrm{~h} /$ aula foi delineada de acordo com a proposta dos três momentos pedagógicos descritos por Delizoicov, Angotti e Pernambuco (2002). Especificamente na sequência didática descrita neste trabalho, a estruturação consistiu na seguinte forma: 
Problematização Inicial ( $1^{a}$ e $2^{a}$ aulas); Organização do Conhecimento ( $3^{a}$, $4^{a}, 5^{a}$ e $6^{a}$ aulas); e Aplicação do Conhecimento (7a, $8^{a}, 9^{a}$ e $10^{a}$ aulas).

No primeiro momento (Problematização Inicial) foi realizada uma atividade prática com a finalidade de sondar os conhecimentos prévios dos alunos sobre o conteúdo, além de problematizar o conhecimento exposto por estes. Nesse momento a turma foi dividida em nove (09) equipes, as quais escolheram dois colegas para a realização da contagem dos batimentos cardíacos em situação de repouso durante 1 (um) minuto e após corrida de 30 (trinta) segundos. As equipes discutiram os resultados e responderam algumas questões previamente elaboradas. Em seguida foi aberta uma discussão envolvendo todas as equipes.

$\mathrm{Na}$ aula seguinte - $3^{a}$ (terceira) aula - foi dado início ao segundo momento pedagógico (Organização do Conhecimento). Nesta aula foi realizada uma exposição dialogada com uso de imagens (em slide) a respeito da constituição geral do sistema cardiovascular bem como sua função. $\mathrm{Na} 4^{a}$ (quarta) aula foi realizada a exibição de animações de curta duração no sentido de abordar o funcionamento do sistema cardiovascular. O título da primeira animação foi "Coração: Como Funciona o Sistema Cardiovascular?" e o da segunda foi "Circulatory System Animation". A cada exibição foi realizada uma discussão para que houvesse um entendimento sobre tudo o que foi abordado nas animações. Tanto na $5^{a}$ (quinta) como na $6^{a}$ (sexta) aula houve a aplicação do jogo "Circulatory System Musical Quiz Heart Quiz (Quiz Sistema Circulatório Musical) com a intenção de integrar os conhecimentos de anatomia já abordados na aula expositiva e os conhecimentos de fisiologia abordados nas animações.

$\mathrm{Na} 7^{\mathrm{a}}$ (sétima) e na $8^{\mathrm{a}}$ (oitava) aulas iniciou-se o terceiro momento pedagógico (Aplicação do Conhecimento). Nestas duas aulas houve uma prática em laboratório que consistiu na dissecação de um coração de galinha. Cada equipe recebeu um roteiro com orientações sobre o procedimento e algumas questões para discussão. Dando continuidade a esse terceiro momento, procedeu-se na $9^{a}$ (nona) e na $10^{a}$ (décima) aulas com a reaplicação das questões da problematização inicial em grupo e a 
aplicação do questionário pós-teste individual.

\section{RESULTADOS E DISCUSSÃO}

\section{Diagnóstico prévio}

O questionário pré-teste contou com 15 questões objetivas visando avaliar o nível de conhecimento da turma acerca do conteúdo de anatomia e fisiologia do sistema cardiovascular. Os resultados são apresentados na tabela 1.

Tabela 1: Resultados das questões objetivas do questionário pré-teste referentes à anatomia e fisiologia do sistema cardiovascular

\begin{tabular}{|c|c|c|c|c|}
\hline Questões & Acertos & Erros & Brancos & Nulas \\
\hline 1. O sistema cardiovascular é constituído de: & $48,7 \%$ & $48,7 \%$ & $2,4 \%$ & $0 \%$ \\
\hline 2. Qual o órgão central do sistema cardiovascular? & $95,1 \%$ & $4,8 \%$ & $0 \%$ & $0 \%$ \\
\hline 3. Qual a principal função do sistema cardiovascular? & $41,4 \%$ & $48,7 \%$ & $7,3 \%$ & $2,4 \%$ \\
\hline $\begin{array}{l}\text { 4. O coração é um importante órgão que apresenta a } \\
\text { seguinte função: }\end{array}$ & $95,1 \%$ & $4,8 \%$ & $0 \%$ & $0 \%$ \\
\hline 5. O coração tem quantas cavidades e quais são elas? & $53,6 \%$ & $43,9 \%$ & $2,4 \%$ & $0 \%$ \\
\hline 6. Quais são os vasos da base do coração? & $31,7 \%$ & $68,2 \%$ & $0 \%$ & $0 \%$ \\
\hline $\begin{array}{l}\text { 7. Quais são os vasos sanguíneos presentes no corpo } \\
\text { humano? }\end{array}$ & $53,6 \%$ & $46,3 \%$ & $0 \%$ & $0 \%$ \\
\hline $\begin{array}{l}\text { 8. Que tipo de transporte sanguíneo é realizado pelas } \\
\text { veias? }\end{array}$ & $9,7 \%$ & $87,8 \%$ & $2,4 \%$ & $0 \%$ \\
\hline $\begin{array}{l}\text { 9. Que estrutura do sistema cardiovascular leva sangue } \\
\text { para os pulmões? }\end{array}$ & $39 \%$ & $58,5 \%$ & $2,4 \%$ & $0 \%$ \\
\hline $\begin{array}{l}\text { 10. Que parte do coração bombeia sangue para o } \\
\text { corpo? }\end{array}$ & $12,1 \%$ & $78 \%$ & $9,7 \%$ & $0 \%$ \\
\hline $\begin{array}{l}\text { 11. Que parte do coração bombeia sangue para os } \\
\text { pulmões? }\end{array}$ & $17 \%$ & $68,3 \%$ & $14,6 \%$ & $0 \%$ \\
\hline $\begin{array}{l}\text { 12. Que parte do coração recebe sangue da veia } \\
\text { cava? }\end{array}$ & $14,6 \%$ & $65,8 \%$ & $19,5 \%$ & $0 \%$ \\
\hline $\begin{array}{l}\text { 13. Que parte do coração recebe sangue da veia } \\
\text { pulmonar? }\end{array}$ & $19,5 \%$ & $63,4 \%$ & $17 \%$ & $0 \%$ \\
\hline $\begin{array}{l}\text { 14. Qual o nome do vaso sanguíneo que é encarregado } \\
\text { de levar sangue do coração para todo o corpo? }\end{array}$ & $53,6 \%$ & $43,9 \%$ & $2,4 \%$ & $0 \%$ \\
\hline $\begin{array}{l}\text { 15. A circulação sanguínea nos mamíferos é dividida em } \\
\text { pequena circulação ou pulmonar e grande circulação } \\
\text { ou sistêmica. A diferença entre elas é que: }\end{array}$ & $48,7 \%$ & $39 \%$ & $12,1 \%$ & $0 \%$ \\
\hline
\end{tabular}

Fonte: Os autores.

A análise dessas respostas demonstra que a turma tinha conhecimento de algumas questões específicas relacionadas ao SC, pois em 33,3\% das questões o índice de acertos superou o índice de erros. Algumas questões 
exigem um conhecimento que está presente no dia a dia das pessoas e são consideradas do senso comum, como as questões 2 e 4, que tratam do coração como órgão central do sistema cardiovascular e sua respectiva função, ambas com 95\% de acerto. Baldissera (2013) afirma ser comum que ao lembrar-se de órgãos vitais do corpo humano se pense em primeiro lugar no coração. Em outras questões que exigem um conhecimento um pouco mais aprofundado, os acertos foram superiores aos erros (questões 5, 7 e 14, todas com $53,6 \%$ de acerto). Acredita-se que o fato da turma já ter estudado o assunto no ano anterior, quando um grupo de alunos preparou e apresentou um seminário, pode ter contribuído para esse percentual de acertos.

As questões que apresentaram um menor índice de acertos foram as questões $8,10,11,12$ e 13. A questão 8 , que buscou saber qual o tipo de transporte sanguíneo realizado pelas veias, apresentou um índice de erro de $87,8 \%$. Isso demonstra que ainda é muito confuso para os estudantes o tipo de sangue (oxigenado ou desoxigenado) que é transportado por esses vasos sanguíneos bem como a definição de veia como vaso responsável pelo transporte de sangue das diversas partes do corpo em direção ao coração. Esse tipo de confusão é comum, pois de maneira geral as pessoas acham que o sangue arterial (rico em oxigênio) é sempre transportado pelas artérias e o sangue venoso (rico em gás carbônico) é sempre transportado pelas veias (SANTOS, 2019).

A questão 10 apresentou um índice de erro de 78\%. A questão 11 teve um índice de erro de $68,3 \%$. Na questão 12 o índice de erro foi de $65,8 \%$, enquanto a questão 13 teve um índice de erro de 63,4\%. Essas questões foram as que apresentaram o maior índice de não marcações. Elas são questões que exigem maior nível de conhecimento de anatomia e fisiologia cardiovascular para afirmar com precisão a função exercida por cada cavidade do coração. Teoricamente esse sistema (e suas estruturas) é muito complexo (CANEPPA et al., 2015). Além disso, os alunos têm dificuldade com a nomenclatura usada em anatomia, o que dificulta também sua 
compreensão da fisiologia, levando-os a não compreender o funcionamento dos sistemas (ALVES et al., 2016; WILLERS et. al., 2013).

Nas demais questões $(1,3,6,9$, e 15) houve menor quantidade de acerto, mas sem muita diferença. Na questão 1, que buscou dos alunos o entendimento sobre a constituição do SC, a quantidade de acertos foi de $48,8 \%$. Os erros apresentados pela maioria dos estudantes demonstra a necessidade de se trabalhar essa questão para que possam conhecer todos os constituintes desse sistema. Na verdade, percebe-se na literatura que trata desse assunto certa diferença na forma de expor a constituição do SC pelos diversos autores. Nesta pesquisa, foi considerado que os constituintes do SC são: coração, vasos sanguíneos, vasos linfáticos, sangue e linfa.

De acordo com Amabis e Martho (2010, p. 372), "O sistema cardiovascular humano, também denominado sistema circulatório, pode ser subdividido em sistema sanguíneo e sistema linfático". Da mesma forma, Linhares e Gewandsznajder (2014), ao organizarem o capítulo sobre sistema circulatório, o apresentam dividido em circulação sistêmica e pulmonar, tendo como componentes o coração e os vasos sanguíneos, e a circulação linfática, tendo como componentes os vasos linfáticos e a linfa. Ainda de acordo com esse mesmo pensamento, Lopes e Rosso (2017, p. 79) dizem que "A função de circulação é realizada pelo sistema cardiovascular, dividido em dois distritos: o sanguíneo e o linfático".

Alguns autores, como Manoel et al. (2015) descrevem que o sistema cardiovascular é formado pelo coração e pelos vasos sanguíneos. Isso pode ter contribuído para que houvesse esse percentual de erros na questão. Por isso, é importante que o professor não se limite ao livro didático adotado pela sua escola e busque outras fontes de informação para que possa abordar os conteúdos da maneira mais correta possível.

Na questão 3, que teve como foco a principal função do SC, mais de $58 \%$ (considerando erros, brancos e nulos) dos estudantes demonstraram necessitar de maior compreensão sobre esse assunto. Destes, a maior parte $(46,3 \%)$ assinalou o controle do funcionamento cerebral e cardíaco como principal função do sistema cardiovascular. Percebe-se assim a necessidade 
de se trabalhar a compreensão do SC como responsável pelo transporte de substâncias dentro do corpo.

A questão 6, que abordou os vasos sanguíneos localizados na base do coração, apresentou 68,3\% de erro, o que revelou dificuldade da maioria da turma quanto a esse conhecimento específico. Essa questão é fundamental para compreender o movimento que o sangue faz na entrada e na saída do coração bem como para compreender questões relacionadas ao trânsito de sangue rico ou pobre em oxigênio, necessário para a manutenção do funcionamento dos tecidos corporais. A questão 9 verificou o entendimento sobre o vaso sanguíneo responsável pelo transporte de sangue para os pulmões, contando com um índice de erro de $58,6 \%$ e questões em branco de $2,4 \%$.

Questões como estas duas últimas apresentam um maior nível de dificuldade por exigir do aluno um conhecimento sólido da nomenclatura das estruturas cardiovasculares, bem como a consciência da exata localização destas e a forma de funcionamento. Brito et al. (2011) afirmam que alguns livros didáticos podem apresentar informações erradas no texto escrito e que, por vezes, esses erros são apresentados também nas imagens disponibilizadas. Os livros avaliados por estes apresentaram uma série de erros quanto à nomenclatura anatômica, utilização de termos desatualizados ou, em alguns casos, incorretos. Os conteúdos sobre sistema cardiovascular estão entre os que têm uma maior quantidade de erros.

A questão 15, que verificou o entendimento sobre a diferença entre os dois circuitos de circulação do sangue, apresentou um índice de erro de $39 \%$. Essa questão, a exemplo das duas anteriores, também exige um bom nível de conhecimento dos estudantes.

A análise desses resultados demonstrou que embora haja certa compreensão dos conteúdos pelos participantes da pesquisa, ainda existem muitas carências em relação à aprendizagem da anatomia e fisiologia do sistema cardiovascular, sobretudo quanto às questões mais complexas e que exigem um maior índice de conhecimento. 
Portanto, os dados coletados por meio deste questionário pré-teste serviram de base para o aprimoramento da sequência didática cuja eficácia foi testada.

\section{Primeiro momento pedagógico: problematização inicial}

Esta etapa de "problematização inicial" influenciou os estudantes a refletirem sobre uma situação cotidiana que exige compreensões acerca do conteúdo que estava sendo proposto para estudo. Essa etapa tem como característica a apresentação de situações reais que estejam relacionadas aos temas abordados (DELIZOICOV; ANGOTTI; PERNAMBUCO, 2002).

Neste momento, os alunos divididos em 09 (nove) equipes realizaram uma atividade prática em que cada grupo escolheu dois de seus membros para fazerem a contagem de seus batimentos cardíacos em situação de repouso e após corrida de trinta segundos. Depois de realizada a contagem e registro dos resultados as equipes passaram a discutir questões apresentadas pela professora.

De acordo com Lima, Siqueira e Costa (2013), as aulas práticas permitem ao professor a chance de fazer com que o aluno perceba um significado próprio para o conteúdo em estudo, podendo relacioná-lo ao cotidiano e trazendo motivação a este.

Depois da contagem inicial dos batimentos cardíacos dentro de sala, cada equipe saiu da sala para espaços abertos onde os alunos testados pudessem realizar a corrida, sendo feita a segunda contagem. Depois os alunos retornaram à sala de aula e passaram a discutir as questões relacionadas à prática desenvolvida. Foi pedido a estes que registrassem suas compreensões no instrumental elaborado para essa etapa da pesquisa. Em seguida foi feita uma discussão no grande grupo, buscando entender melhor o pensamento de cada equipe. As questões discutidas e algumas respostas dadas pelas equipes encontram-se no quadro 1. 
Quadro 1: Questionamentos da problematização inicial com algumas respostas dadas pelas equipes

\begin{tabular}{|c|c|}
\hline Questões & Algumas respostas dadas pelas equipes \\
\hline $\begin{array}{l}\text { 1. Houve diferença } \\
\text { entre os batimentos } \\
\text { cardíacos de uma } \\
\text { situação para a } \\
\text { outra? Por quê? }\end{array}$ & $\begin{array}{l}\text { "Sim, ao exercermos algum esforço físico nossos batimentos se } \\
\text { tornam mais acelerados" (G-1). } \\
\text { "Sim, por causa do esforço físico" (G-2). } \\
\text { "Sim, por que houve energia gasta devido ao esforço físico" (G-7). } \\
\text { "Sim, pois após a corrida o nosso corpo precisava de mais oxigênio } \\
\text { e a resposta do nosso coração foi bombear mais sangue para } \\
\text { nossa corrente sanguínea" (G-8). }\end{array}$ \\
\hline $\begin{array}{l}\text { 2. O que significa o } \\
\text { som das batidas do } \\
\text { coração? }\end{array}$ & $\begin{array}{l}\text { "O bombeamento de sangue pelo corpo" (G-2). } \\
\text { "A força e a pulsação que o coração bombeia" (G-5). } \\
\text { "Está recebendo sangue rico em gás carbônico e pulsando gás } \\
\text { oxigênio para o corpo" (G-8). }\end{array}$ \\
\hline $\begin{array}{l}\text { 3. Onde está } \\
\text { localizado o pulso? }\end{array}$ & $\begin{array}{l}\text { "Próximo ao osso chamado rádio" (G-2). } \\
\text { "Pulso braquial" (G-3). } \\
\text { "O nosso corpo possui várias localizações para o pulso. Por } \\
\text { exemplo: no pescoço, fêmur, tíbia, braço e etc." (G-7). } \\
\text { "Parte interna do braço, próximo ao punho" (G-8). }\end{array}$ \\
\hline $\begin{array}{l}\text { 4. Que tipo de vaso } \\
\text { sanguíneo é usado } \\
\text { para a percepção } \\
\text { da pulsação? }\end{array}$ & "Artéria" (G-1). \\
\hline $\begin{array}{l}\text { 5. Por que os } \\
\text { batimentos } \\
\text { cardíacos podem } \\
\text { ser medidos pelo } \\
\text { pulso? }\end{array}$ & $\begin{array}{l}\text { "Não respondeu" (G-1). } \\
\text { "Porque tem ligações na mesma artéria" (G-3). }\end{array}$ \\
\hline $\begin{array}{l}\text { 6. Para que o } \\
\text { sangue chega ao } \\
\text { local do pulso? }\end{array}$ & $\begin{array}{l}\text { "Não respondeu" (G-3). } \\
\text { "Para levar oxigênio" (G-4). } \\
\text { "Porque há transporte de sangue para todo o corpo" (G-6). }\end{array}$ \\
\hline
\end{tabular}

Fonte: Os autores.

No primeiro questionamento indagou-se aos estudantes se houve diferença entre os batimentos cardíacos de uma situação para outra e por quê. Todas as equipes afirmaram que "sim" e relataram que na segunda contagem observou-se um número maior de batimentos cardíacos. No entanto, apenas as equipes G-1 e G-2 apresentaram uma justificativa parcialmente satisfatória ao dizerem que o esforço físico acelera os batimentos cardíacos e, em consequência, aumenta a circulação do sangue. Contudo, não foram capazes de entender o motivo pelo qual isso acontece. Já a G-7 relacionou o aumento dos batimentos cardíacos à maior necessidade energética, mas não explicou como o aumento dos batimentos contribuiu para a liberação de energia. A G-8 demonstrou ter compreendido 
a necessidade do aumento do aporte de oxigênio para o corpo na segunda situação, mas não fez menção ao papel do oxigênio nesse processo.

Depois do posicionamento de cada equipe, novos questionamentos foram feitos de acordo com a necessidade verificada. Aos poucos, novas reflexões foram geradas e as compreensões dos alunos iam se encaixando umas nas outras, havendo uma complementação de conhecimentos ou percepção da necessidade de novas aprendizagens.

De acordo com as discussões em relação a essa questão, verificou-se uma carência de aprendizagem no tocante à compreensão da função do sistema circulatório que, de acordo com Silverthorn (2017), é a de transportar substâncias para todas as partes do corpo, fornecendo oxigênio e nutrientes para o processo metabólico de produção de energia pelas células. As respostas apresentadas pelos estudantes em relação a esta questão diferem, em parte, dessa definição, pois alguns compreendem que ocorre transporte de oxigênio, mas não conseguem compreender que outras substâncias também são transportadas, nem tampouco o papel do oxigênio nesse processo. Observou-se ainda uma falta de compreensão acerca da integração entre os sistemas circulatório e respiratório.

No segundo questionamento, que buscou saber dos estudantes o que significa o som das batidas do coração, seis grupos responderam que é o bombeamento sanguíneo, evidenciando que os estudantes destes grupos entendem parcialmente os fatores que induzem os batimentos cardíacos, pois é após o bombeamento que as válvulas se fecham, produzindo o som. No entanto, os grupos não sabem que o som das batidas do coração é decorrente do fechamento das válvulas atrioventriculares e semilunares após a passagem de sangue (SILVERTHORN, 2017). A dificuldade apresentada pode ter decorrido da especificidade dessa informação e da dificuldade de se compreender aspectos complexos inerentes a esse sistema (CANEPPA et al., 2015).

Em relação à terceira questão, que buscou saber destes onde está localizado o pulso, apenas uma equipe respondeu de forma correta ao afirmar que existem vários locais onde este pode ser localizado. De maneira 
geral, o pensamento era de que o pulso estava localizado no braço, mais precisamente no punho. Durante a discussão percebeu-se que a maioria da turma não apresentou conhecimento suficiente sobre essa questão.

Sobre o quarto questionamento, que indagou que tipo de vaso é usado para a percepção da pulsação, a maioria das equipes respondeu corretamente. Seis (06) equipes disseram ser a artéria, enquanto três (03) equipes não responderam.

O quinto questionamento procurou saber por que razões os batimentos cardíacos podem ser medidos pelo pulso. Cinco (05) equipes não responderam a essa pergunta, enquanto as demais apresentaram respostas sem clareza, como verificado na resposta da G-3. De acordo com Silverthorn (2017), o pulso é uma onda de pressão que é percebida quando o coração, por meio do ventrículo esquerdo, empurra o sangue para dentro da aorta, sendo transmitido ao longo das artérias.

O último questionamento induziu os alunos a refletirem sobre por qual motivo o sangue chega ao local do pulso. Cinco equipes responderam de maneira incompleta, sendo que três delas disseram que seria para levar oxigênio, demonstrando compreender a função de transporte exercida pelo sistema cardiovascular. Contudo, dizer que a função se resume ao transporte de oxigênio é uma visão limitada, evidenciando a necessidade de mais informação sobre o assunto. Quatro equipes não responderam.

Essa etapa foi finalizada com uma paródia que promoveu um momento descontraído ao mesmo tempo que apresentou a ementa e os objetivos da sequência didática a ser aplicada.

É importante ressaltar que nesse momento pedagógico não houve explicações conclusivas, pois o intuito era perceber as compreensões já existentes e aguçar a curiosidade dos estudantes em relação ao conteúdo, além de fazê-los compreender suas carências de aprendizagem (DELIZOICOV; ANGOTTI; PERNAMBUCO, 2002).

\section{Segundo momento pedagógico: organização do conhecimento}


Esse momento foi iniciado com a exposição dialogada. O conteúdo foi trabalhado de forma interativa, buscando-se sempre a participação dos estudantes por meio do diálogo, onde estes puderam contribuir com seus conhecimentos acerca do assunto e também expondo suas dúvidas. Depois da exposição dos objetivos da aula, iniciou-se com o seguinte questionamento: "Qual a constituição do sistema cardiovascular?". Pelo diálogo entre a professora e os estudantes percebeu-se que a compreensão geral da turma era de que seriam o coração e os vasos sanguíneos. Nesse momento foi feita uma explicação geral sobre o que seriam os vasos linfáticos e a linfa no sentido de esclarecer que ambos fazem parte do sistema cardiovascular. Depois dessa explicação eles compreenderam, mas disseram não saber sobre isso antes, pois pelo que já tinham visto sobre esse sistema, só faziam parte o coração, os vasos sanguíneos e o sangue.

Depois disso, passou-se a estudar a localização do coração no corpo humano. Antes de visualizar a imagem em slide perguntou-se aos alunos onde realmente o coração está localizado. A maioria deles já soube dizer que a posição do coração é central com uma inclinação para o lado esquerdo, no entanto, julgou-se necessário trazer uma descrição mais detalhada dessa posição.

Em seguida foram apresentadas as camadas do coração (pericárdio, miocárdio e endocárdio), informação que seria usada como subsídio para a aula prática no momento final da sequência didática. Nesse momento, foi apresentada sua estrutura, posição e função. A maioria dos alunos demonstrou não ter conhecimento sobre essas partes do coração, sendo um conhecimento importante a mais para a compreensão geral do SC. Depois disso foi perguntado aos estudantes quais seriam os vasos da base do coração. Estes demonstraram não entender a pergunta.

Após algumas perguntas feitas pelos alunos apresentou-se uma imagem em slide com um coração e os vasos da base, além das artérias coronárias e veias cardíacas. A explanação seguiu-se com a apresentação da anatomia externa e interna do coração. Na discussão os alunos demonstraram ter conhecimento sobre a existência das estruturas 
envolvidas, mas tendo dificuldade em relação à nomenclatura das valvas, dos átrios e dos ventrículos.

Percebeu-se um bom aproveitamento nesta aula, onde se privilegiou a exposição dialogada do conteúdo, favorecendo a participação dos estudantes. Para Anastasiou e Alves (2005), na aula expositiva dialogada, a principal diferença em relação à aula expositiva tradicional é a participação do estudante, que tem seu ponto de vista levado em consideração, sendo analisado e respeitado.

Depois de ser apresentada a estrutura anatômica do SC por meio da aula expositiva dialogada foi o momento de, na quarta aula, utilizar o recurso didático das animações em vídeo como subsídio para as discussões sobre os seus aspectos fisiológicos. Dessa forma, o assunto foi aprofundado aos poucos, procurando-se aumentar a complexidade paulatinamente, seguindo o pensamento de Zabala (1998), que diz que as atividades de uma sequência didática devem ser encadeadas considerando um nível hierárquico de complexidade.

Essa aula veio complementar a aula anterior, relacionando as estruturas apresentadas com suas respectivas funções. De acordo com Gonçalves, Veit e Silveira (2006), esta é uma das maneiras que as animações podem ser utilizadas, ou seja, complementando explicações dadas pelo professor na exposição do conteúdo.

Logo após a apresentação da primeira animação os alunos foram questionados sobre que aspectos apresentados lhes chamaram mais atenção no sentido de trazer algum entendimento novo. Rapidamente alguém se pronunciou dizendo que foi sobre como é produzido o som das batidas do coração. Durante a problematização inicial os estudantes apresentaram uma compreensão apenas parcial sobre essa questão. O conhecimento prévio destes foi importante para que, ao assistirem a animação, chegassem à compreensão de que durante esse bombeamento sanguíneo ocorre a abertura e o fechamento das valvas atrioventriculares e semilunares.

A indagação de um estudante gerou uma discussão que possibilitou a

Revista Exitus, Santarém/PA, Vol. 10, p. 01-31, e020099, 2020. 
compreensão de que as contrações cardíacas decorrem de descarga elétrica gerada no nó sinoatrial, como demonstrado na animação. Aqui fica evidente a importância do conhecimento prévio apresentado pelos alunos, concordando com Baldissera (2013), que assevera a importância de relacionar o conhecimento novo com o que o aluno já possui, criando um conflito cognitivo que promove uma reorganização de conceitos e uma aprendizagem significativa.

Depois de exibida a segunda animação foi feito o mesmo questionamento motivador para a discussão inicial: Quais aspectos Ihes chamaram mais atenção por trazer algum entendimento novo? Dessa vez percebeu-se uma maior dificuldade destes para responder à pergunta, mas, ao insistir, um deles fez um comentário que favoreceu uma nova discussão sobre a função do SC. Diante de algumas dúvidas que persistiram foi feita a repetição pausada da animação e a discussão de alguns aspectos, como o fluxo sanguíneo na circulação pulmonar e na circulação sistêmica. Nesse aspecto, os alunos já tinham demonstrado pouco conhecimento anteriormente, fato que foi evidenciado por questões com menor índice de acerto no questionário pré-teste.

A utilização desse recurso estimulou a participação dos estudantes e a interação com os colegas na busca pela compreensão por meio do diálogo proporcionado pelas animações apresentadas.

A utilização do Jogo Didático (Quiz) propiciou um momento agradável e descontraído de aprendizagem que promoveu a participação de todos os alunos. Almeida et al. (2016) mencionam a possibilidade da utilização de jogo do tipo "Quiz" para avaliar os estudantes de uma forma diferente, sem o peso da avaliação tradicional, mas com a empolgação que os jogos trazem. No decorrer da SD foram vários os momentos de avaliação realizados, sendo verificado o desenvolvimento dos alunos a cada aula. Para Pereti e Tonin da Costa (2013), esse processo avaliativo contínuo no decorrer da SD faz parte das características dessa metodologia de ensino.

Considerando uma compreensão cada vez mais aprofundada dos conteúdos, buscou-se, por meio do jogo, integrar os conhecimentos de 
anatomia já abordados na aula expositiva dialogada e os conhecimentos de fisiologia trabalhados por meio das animações. Na opinião de Almeida et al. (2016) o jogo pode ser um aliado do processo educacional, motivando os alunos a um engajamento efetivo na construção da sua própria aprendizagem.

Percebeu-se, nessa atividade, que o envolvimento, a participação e a atenção nas discussões sobre as questões do jogo promoveram os acertos posteriores. Esse aspecto dos jogos também foi percebido por Silva (2015), quando os participantes de um jogo de tabuleiro notaram que quando algumas perguntas se repetiam havia mais facilidade para responder corretamente.

\section{Terceiro momento pedagógico: aplicação do conhecimento}

Essa etapa da sequência didática envolveu três atividades: Prática de dissecação de coração de galinha; Reaplicação do questionário da problematização inicial; e aplicação do questionário pós-teste.

Nas $8^{a}$ e $9^{a}$ aulas realizou-se a prática de dissecação de corações de galinha. Cada equipe recebeu o material necessário à realização da prática e um roteiro explicativo sobre o procedimento a ser realizado e algumas questões para a facilitação da discussão dentro do grupo. Depois das orientações iniciais, os estudantes tiveram autonomia para realizar o procedimento e encontrar as respostas para as questões propostas.

Depois de realizado o procedimento, os alunos passaram a escrever aquilo que tinham conseguido construir como respostas para as indagações. Neste momento houve uma participação ativa da maioria deles. Ficou evidente que por meio da prática os estudantes se sentiram capazes de colaborar com maior segurança para a sistematização das respostas. Esse aspecto corrobora com o que dizem Soares e Baiotto (2015, p. 57) quando afirmam que "as atividades práticas em sala de aula proporcionam ao educando a oportunidade de ser ativo, participante e seguro de suas decisões".

De maneira geral, as respostas escritas foram satisfatórias e todas as 
equipes demonstraram bom nível de aprendizagem, considerando-se que essa estratégia contribuiu significativamente para a aprendizagem do conteúdo de anatomia e fisiologia do SC.

Os questionamentos realizados na problematização inicial foram reaplicados. As respostas dadas por algumas equipes para cada questão nos dois momentos estão apresentadas no quadro 2.

Quadro 2: Reaplicação dos Questionamentos da problematização inicial com algumas respostas dadas no início e no final da SD

\begin{tabular}{|c|c|c|}
\hline Questões & $\begin{array}{l}\text { Algumas respostas dadas por } \\
\text { algumas equipes no início da SD }\end{array}$ & $\begin{array}{l}\text { Algumas respostas dadas } \\
\text { mesmas equipes no final da SD }\end{array}$ \\
\hline $\begin{array}{l}\text { 1. Houve } \\
\text { diferença } \\
\text { entre os } \\
\text { batimentos } \\
\text { cardíacos } \\
\text { de uma } \\
\text { situação } \\
\text { para a } \\
\text { outra? Por } \\
\text { quê? }\end{array}$ & $\begin{array}{l}\text { "Sim, ao exercermos algum esforço } \\
\text { físico nossos batimentos se tornam } \\
\text { mais acelerados" (G-1). } \\
\text { "Sim, por causa do esforço físico" } \\
\text { (G-2). }\end{array}$ & $\begin{array}{l}\text { "Sim, por a movimentação do corpo } \\
\text { necessitar de uma maior energia, } \\
\text { aumentando o fluxo sanguíneo e } \\
\text { pressão com que chega ao coração" } \\
\text { (G-1). } \\
\text { "Sim, porque quando está em repouso } \\
\text { o coração bombeia menos sangue. } \\
\text { Ao praticarmos exercícios físicos há um } \\
\text { maior desgaste de energia, fazendo o } \\
\text { coração bombear mais sangue, pois } \\
\text { as células necessitam de mais oxigênio } \\
\text { para novamente produzir energia" (G- } \\
\text { 2). } \\
\text { "Sim, devido ao intenso esforço, houve } \\
\text { uma necessidade de maior circulação } \\
\text { no corpo, causando assim o aumento } \\
\text { dos batimentos do coração para o } \\
\text { fornecimento de energia" (G-7). } \\
\text { "Sim, um aumento na aceleração } \\
\text { cardíaca por conta dos movimentos } \\
\text { irá ter maior gasto de energia, } \\
\text { precisará maior oxigenação, maior } \\
\text { frequência do sangue oxigenado } \\
\text { gerado pela hematose" (G-8). }\end{array}$ \\
\hline $\begin{array}{l}\text { 2. } \bigcirc \text { que } \\
\text { significa o } \\
\text { som das } \\
\text { batidas do } \\
\text { coração? }\end{array}$ & $\begin{array}{l}\text { "A força e a pulsação que o } \\
\text { coração bombeia" (G-5). } \\
\text { "Está recebendo sangue rico em } \\
\text { gás carbônico e pulsando gás } \\
\text { oxigênio para o corpo" (G-8). }\end{array}$ & $\begin{array}{l}\text { "Sistólica é a abertura e contração das } \\
\text { válvulas tricúspide, mitral e dos } \\
\text { ventrículos. Diastólica é a abertura e } \\
\text { contração das válvulas semilunares e } \\
\text { dosátrios" (G-2). } \\
\text { "Abertura das válvulas no coração } \\
\text { para bombeamento do sangue } \\
\text { (sistólica e diastólica)" (G-5). } \\
\text { "Significa que o sangue está sendo } \\
\text { bombeado para ser mandado para o } \\
\text { nosso corpo nos fornecendo sangue } \\
\text { rico em oxigênio" (G-8). }\end{array}$ \\
\hline $\begin{array}{l}\text { 3. Onde } \\
\text { está } \\
\text { localizado }\end{array}$ & $\begin{array}{l}\text { "Próximo ao osso chamado rádio" } \\
\text { (G-2). }\end{array}$ & $\begin{array}{l}\text { "Carotídeo fica no pescoço; radial no } \\
\text { punho; braquial no braço; umeral no } \\
\text { úmero; femural na região inguinal etc." }\end{array}$ \\
\hline
\end{tabular}




\begin{tabular}{|c|c|c|}
\hline o pulso? & $\begin{array}{l}\text { "O nosso corpo possui várias } \\
\text { localizações para o pulso. Por } \\
\text { exemplo: no pescoço, fêmur, tíbia, } \\
\text { braço e etc." (G-7). } \\
\text { "Parte interna do braço, próximo } \\
\text { ao punho" (G-8). }\end{array}$ & $\begin{array}{l}\text { (G-2). } \\
\text { "Espalhado ao longo das demais } \\
\text { regiões do corpo, e recebem } \\
\text { diferentes nomes como o radial, } \\
\text { carotidal, femural, pedial, braquial" (G- } \\
\text { 3). } \\
\text { "Nosso corpo dispõe de várias } \\
\text { localizações, ex: femural, radial, } \\
\text { braquial, apical, frontal, tibial" (G-7). } \\
\text { "Na artéria radial, femural, carótida, } \\
\text { apical" (G-8). }\end{array}$ \\
\hline $\begin{array}{l}\text { 4. Que tipo } \\
\text { de vaso } \\
\text { sanguíneo } \\
\text { é usado } \\
\text { para a } \\
\text { percepção } \\
\text { da } \\
\text { pulsação? }\end{array}$ & $\begin{array}{l}\text { "Artéria" (G-1). } \\
\text { "Não respondeu" (G-5). }\end{array}$ & $\begin{array}{l}\text { "Artéria" (G-1). } \\
\text { "Artéria" (G-5). }\end{array}$ \\
\hline $\begin{array}{l}\text { 5. Por que } \\
\text { os } \\
\text { batimentos } \\
\text { cardíacos } \\
\text { podem ser } \\
\text { medidos } \\
\text { pelo pulso? }\end{array}$ & $\begin{array}{l}\text { "Porque tem ligações na mesma } \\
\text { artéria" (G-3). }\end{array}$ & $\begin{array}{l}\text { "Porque tanto no coração quanto na } \\
\text { circulação cardiovascular a passagem } \\
\text { do sangue é feita por uma pressão } \\
\text { exercida, no caso do pulso existe uma } \\
\text { sensibilidade maior, por a pressão ser } \\
\text { maior" (G-1). } \\
\text { "Pois o coração bombeia sangue para } \\
\text { as demais regiões do corpo através } \\
\text { das artérias, fazendo com que seja } \\
\text { possível a aferição e percepção dos } \\
\text { batimentos" (G-3). }\end{array}$ \\
\hline $\begin{array}{l}\text { 6. Para que } \\
\text { o sangue } \\
\text { chega ao } \\
\text { local do } \\
\text { pulso? }\end{array}$ & $\begin{array}{l}\text { "Não respondeu" (G-3). } \\
\text { "Para levar oxigênio" (G-4). } \\
\text { "Porque há transporte de sangue } \\
\text { para todo o corpo" (G-6). }\end{array}$ & $\begin{array}{l}\text { "Para transportar oxigênio e nutrientes } \\
\text { as diversas células do corpo" (G3). } \\
\text { "Para transportar sangue e outros } \\
\text { nutrientes para essa determinada } \\
\text { parte do corpo" (G4). } \\
\text { "Para haver irrigação em todas as } \\
\text { partes do corpo" (G6). }\end{array}$ \\
\hline
\end{tabular}

Fonte: Os autores.

Em relação ao primeiro questionamento da problematização inicial, $66,7 \%$ das equipes responderam de forma errada ou de forma insatisfatória (como as respostas do G1 e G2), 11,1\% não respondeu, 33,3\% apresentaram respostas parcialmente corretas (como a do G7) e nenhuma equipe respondeu de forma completamente correta. Já nas respostas apresentadas na etapa de aplicação do conhecimento, apenas $11,1 \%$ respondeu de forma errada, 55,5\% apresentaram respostas parcialmente corretas (como a do G7) e 22,2\% apresentaram respostas completas (como a dos grupos G2 e 
G8), verificando-se assim uma melhoria significativa em relação à primeira aplicação.

Na segunda questão, no momento inicial, $66,7 \%$ das equipes demonstraram ter certa compreensão sobre o que provoca o som das batidas do coração, mas não apresentando o conhecimento específico sobre as estruturas que fazem parte do processo e do modo como este ocorre, 22,2\% apresentaram respostas erradas e 11,1\% não responderam. No momento final, 55,5\% demonstraram ter adquirido uma compreensão parcial e 44,4\% conseguiram compreender melhor o principal foco dessa questão.

$\mathrm{Na}$ terceira questão, $77,7 \%$ dos grupos demonstraram ter aprendido sobre a localização do pulso no corpo humano, abandonando a concepção inicial errônea (como os grupos G2, G3 e G8), enquanto 11,1\%, que já tinham uma compreensão correta sobre esse aspecto, a mantiveram (como o G7), e 11,1\% continuaram com uma concepção errônea.

Em relação ao quarto questionamento, $66,7 \%$ das equipes já tinham acertado na problematização inicial dizendo que a artéria é o tipo de vaso utilizado para a percepção da pulsação, enquanto $33,3 \%$ das equipes não havia respondido. Já no momento final de aplicação do conhecimento, todas as equipes acertaram essa questão.

Para $\circ 5^{\circ}$ (quinto) questionamento, na situação inicial, 55,5\% não responderam e $44,4 \%$ demonstraram não ter clareza sobre a resposta. Na situação final, 66,7\% apresentaram uma resposta correta (como o G1 e o G3) e apenas $33,3 \%$ ainda apresentaram uma compreensão equivocada.

Em relação ao último questionamento, na problematização inicial, $44,4 \%$ das equipes não responderam, 22,2\% responderam de forma errada e $33,3 \%$ deram uma resposta parcialmente correta. Já na etapa de aplicação do conhecimento, $44,4 \%$ das equipes trouxeram respostas parciais e $22,2 \%$ trouxeram respostas mais completas.

Pelos resultados, pode-se perceber a evolução da aprendizagem em todos os aspectos investigados, de maneira que a mudança conceitual fica evidente, sinalizando para o êxito da metodologia aplicada.

A aplicação do questionário pós-teste (contendo as mesmas questões

Revista Exitus, Santarém/PA, Vol. 10, p. 01-31, e020099, 2020. 
contidas no pré-teste) foi feita como forma de avaliar o conhecimentos dos estudantes após o trabalho com a SD. A comparação entre os resultados das respostas obtidas antes e depois da SD pode ser observada na tabela 2.

Tabela 2: Comparação dos resultados das respostas antes e depois da SD

\begin{tabular}{cccc}
\hline Questões & $\begin{array}{c}\text { \% de acertos antes } \\
\text { da SD }\end{array}$ & $\begin{array}{c}\text { \% de acertos depois } \\
\text { da SD }\end{array}$ & \% de desempenho \\
\hline $\mathbf{1}$ & $49 \%$ & $32 \%$ & $-17 \%$ \\
$\mathbf{2}$ & $95 \%$ & $100 \%$ & $5 \%$ \\
$\mathbf{3}$ & $41 \%$ & $80 \%$ & $39 \%$ \\
$\mathbf{4}$ & $95 \%$ & $100 \%$ & $5 \%$ \\
$\mathbf{5}$ & $54 \%$ & $95 \%$ & $41 \%$ \\
$\mathbf{6}$ & $32 \%$ & $97 \%$ & $65 \%$ \\
$\mathbf{7}$ & $54 \%$ & $80 \%$ & $26 \%$ \\
$\mathbf{8}$ & $10 \%$ & $32 \%$ & $22 \%$ \\
$\mathbf{9}$ & $39 \%$ & $71 \%$ & $32 \%$ \\
$\mathbf{1 0}$ & $12 \%$ & $54 \%$ & $42 \%$ \\
$\mathbf{1 1}$ & $17 \%$ & $63 \%$ & $46 \%$ \\
$\mathbf{1 2}$ & $15 \%$ & $85 \%$ & $70 \%$ \\
$\mathbf{1 3}$ & $19 \%$ & $88 \%$ & $69 \%$ \\
$\mathbf{1 4}$ & $54 \%$ & $88 \%$ & $34 \%$ \\
$\mathbf{1 5}$ & $49 \%$ & $90 \%$ & $41 \%$ \\
\hline
\end{tabular}

Fonte: Os autores.

Os resultados demonstram que em 14 das 15 questões (exceção apenas da questão 1) houve um aumento considerável no número de acertos após a aplicação da SD. Enquanto o questionário pré-teste apresentou apenas 33\% das questões com acertos superando a quantidade de erros, o pós-teste apresentou $87 \%$ das questões em que os acertos superaram a quantidade de erros.

Em relação à primeira questão, que buscou evidenciar a compreensão dos alunos sobre a constituição do SC, é possivel considerar algumas hipóteses para a redução do número de acertos no pós-teste. É possível que o fato dos estudantes terem sido submetidos ao estudo de alguns autores no ensino fundamental (que apresentavam apenas 0 coração e os vasos sanguíneos ou apenas o coração, os vasos sanguíneos e o sangue como componentes do SC) ou mesmo a falta de concordância entre alguns autores do ensino médio tenham causado certa confusão na hora de assinalar a resposta. Outra explicação que pode ser considerada é 
o fato deste aspecto ter sido trabalhado apenas durante a aula expositiva dialogada, não tendo sido mais contemplado por meio das outras estratégias metodológicas utilizadas.

Em relação às questões 2 e 4 , os estudantes já tinham apresentado bom índice de acerto no questionário pré-teste (95\%) e 100\% acertaram após a aplicação da SD. Essas duas questões são tidas como questões fáceis por apresentar conceitos que fazem parte do senso comum.

$\mathrm{Na}$ terceira questão observa-se que antes da aplicação da SD, o índice de acertos foi de $41 \%$, enquanto após a aplicação da SD foi de $80 \%$, significando um aumento de $39 \%$ no índice de acertos. Essa questão buscava entendimento sobre a função do sistema cardiovascular. Este aspecto foi bem evidenciado por meio das animações e das discussões que delas emanaram. De acordo com Mendes (2010), as animações servem bem ao estudo de eventos dinâmicos, sendo boas para esclarecer processos que envolvem movimento, como no caso em questão.

A quinta questão, que indagou sobre quantas e quais são as cavidades do coração, apresentou um índice de acerto, no pré-teste, de $54 \%$, e no pós-teste, de $95 \%$, tendo um aumento de $41 \%$ no percentual de respostas corretas depois da aplicação da SD. Já a questão de número 6 (sobre quais são os vasos da base do coração) teve $32 \%$ como percentual de acertos no pré-teste e $97 \%$ no pós-teste, representando um aumento de $65 \%$ de acertos após a aplicação da SD. Os conhecimentos referentes a essas duas questões foram abordados durante a SD, sobretudo pelo uso do jogo didático e pela atividade prática em laboratório.

Fica evidente que o uso de estratégias variadas para o trabalho de conteúdos complexos resulta em um efeito positivo. Corroborando com esse pensamento, Sant'anna (2017) diz que se houver um planejamento de aulas com diferentes estilos metodológicos é possível atrair a atenção de um número maior de alunos e alcançar resultados satisfatórios de aprendizagem.

A questão 7, que buscou a compreensão sobre o nome dos vasos sanguíneos, teve um índice de acerto de 54\% antes da aplicação da SD e 
de $80 \%$ depois da aplicação (aumento no número de acertos de $26 \%$ no pós-teste). Já a questão 8, que indagou sobre o tipo de transporte sanguíneo realizado pelas veias, apresentou $10 \%$ de acerto no pré-teste e de $32 \%$ no pós-teste (aumento de $22 \%$ depois da aplicação da SD). O conhecimento exigido nessas questões pode ser considerado de nível elevado, sobretudo pelo fato dos alunos apresentarem uma compreensão popular de que as veias sempre carregam sangue venoso (SANTOS, 2019). Os aspectos referentes a estas duas questões foram trabalhados na SD por meio da exposição dialogada e das animações, proporcionando um ganho de aprendizagem evidenciado pelo aumento percentual apresentado.

A questão 9 buscou saber qual a compreensão dos alunos sobre que estrutura do SC leva sangue para os pulmões. Nesta questão, o índice de acerto no pré-teste foi de $39 \%$, enquanto no pós-teste foi de $71 \%$ (aumento percentual de $32 \%$ após a aplicação da SD). Esta é uma questão considerada mais complexa por exigir tanto a compreensão da nomenclatura da estrutura como sua função no SC. O conhecimento referente a essa questão foi trabalhado principalmente por meio das animações e do jogo didático. Pode-se inferir que estes procedimentos didáticos favoreceram aos alunos novas formas de aprender e desenvolverse (DOMINGOS JÚNIOR et al., 2018).

As questões 10, 11, 12 e 13 foram as que, juntamente com a 8 , apresentaram o menor índice de acertos no pré-teste. A questão 10, que tratou sobre a parte do coração que bombeia sangue para o corpo, teve um percentual de acerto no pré-teste de apenas $12 \%$, já no pós-teste foi de $54 \%$, (aumento de $42 \%$ após a aplicação da SD). Em relação à questão 11 , que indagou sobre que parte do coração bombeia sangue para os pulmões, o índice de acerto no pré-teste foi de 17\%, enquanto que no pósteste foi de $63 \%$ (aumento de $46 \%$ após a aplicação da SD). Na questão 12 , que perguntou que parte do coração recebe sangue da veia cava, o percentual de acertos foi de $15 \%$ no pré-teste e de $85 \%$ no pós-teste (aumento de $70 \%$ após a aplicação da SD). Já a questão 13, que perguntou que parte do coração recebe sangue da veia pulmonar, apresentou um 
percentual de acerto de $19 \%$ no pré-teste e de $88 \%$ no pós-teste (aumento de $69 \%$ no número de acertos). Essas quatro questões eram as mais complexas por exigir o conhecimento da nomenclatura básica das estruturas mencionadas e a compreensão fisiológica dos eventos. Alguns autores, como Alves et al. (2016), Barbosa, Ramos e Sereia (2010), Caneppa et al. (2015), Jesus (2014) e Willers et al. (2013), corroboram com este pensamento ao considerarem o estudo da anatomia e fisiologia complexo devido à grande quantidade de estruturas que precisam ser memorizadas e à compreensão do sequenciamento de eventos e reações a elas relacionados. Os conhecimentos referentes a estas questões foram trabalhados por meio de todas as estratégias utilizadas na SD, aumentandose gradativamente o nível de complexidade e aprofundamento.

A questão 14, que buscou saber o conhecimento dos estudantes sobre o vaso sanguíneo que leva sangue do coração para todo o corpo, contou com um índice de $54 \%$ de acerto no pré-teste e de $88 \%$ no pós-teste, apresentando um desempenho de $34 \%$ após a aplicação da SD. O conteúdo referente a esta questão foi trabalhado na SD, sobretudo pelo uso das animações e do jogo didático. Dias e Chagas (2015) concluíram que o uso de animações influencia de forma positiva a dinâmica das aulas e facilita a compreensão de conceitos quando exploradas por meio de metodologias ativas centradas no aluno. Da mesma forma, Campos, Bortoloto e Felício (2003) dizem que o jogo didático se caracteriza como uma importante e viável alternativa para auxiliar os processos de ensino e aprendizagem, favorecendo a construção do conhecimento ao aluno.

Finalmente, na questão 15, perguntou-se sobre a diferença entre circulação pulmonar e sistêmica. Essa questão contou com um índice de acerto de $49 \%$ no pré-teste, enquanto que no pós-teste esse índice foi de 90\% (um aumento de $41 \%$ no número de acertos após a aplicação da SD). A estratégia usada nesta SD que trabalhou esse aspecto de forma mais direta foram as animações. No caso desta questão 15, a exemplo da questão 3 , evidencia-se que as animações foram importantes para esclarecer processos que envolvem movimento, como afirma Mendes (2010). 
Ainda trabalhando com o resultado dos questionários pré e pós-teste, foi realizada uma análise do percentual de acertos comparando-se o préteste ao pós-teste, aluno por aluno. O resultado mostrou que 38 (trinta e oito) alunos (90\%) apresentaram um aumento no percentual de acertos após a aplicação da SD. Devido à quantidade de participantes da pesquisa ser grande, optou-se por realizar uma síntese do resultado na tabela 3.

Tabela 3: Aumento percentual no número de acertos após aplicação da SD por grupos de alunos que apresentaram um percentual de aumento comum

\begin{tabular}{ccc}
\hline $\begin{array}{c}\text { \% de aumento no número de } \\
\text { acertos após a aplicação da } \\
\text { SD }\end{array}$ & $\begin{array}{c}\text { Quantidade de alunos que } \\
\text { apresentaram esse aumento } \\
\text { percentual }\end{array}$ & $\begin{array}{c}\text { Alunos que apresentaram } \\
\text { esse aumento percentual }\end{array}$ \\
\hline $7 \%$ & 03 & $\mathrm{~A} 13, \mathrm{~A} 27$ e A41 \\
$13 \%$ & 01 & $\mathrm{~A} 8$ \\
$14 \%$ & 01 & $\mathrm{~A} 25$ \\
$20 \%$ & 04 & $\mathrm{~A} 1, \mathrm{~A} 7, \mathrm{~A} 10$ e A35 \\
$27 \%$ & 03 & $\mathrm{~A} 17, \mathrm{~A} 28$ e A36 \\
$33 \%$ & 04 & $\mathrm{~A} 14, \mathrm{~A} 18, \mathrm{~A} 29$ e A37 \\
$34 \%$ & 02 & $\mathrm{~A} 15$ A38 \\
$40 \%$ & 06 & $\mathrm{~A} 9$ e A24 \\
$46 \%$ & 02 & $\mathrm{~A} 2, \mathrm{~A} 32$ e A33 \\
$47 \%$ & 03 & $\mathrm{~A} 4$ e A23 \\
$53 \%$ & 02 & $\mathrm{~A} 12$ e A31 \\
$54 \%$ & 02 & $\mathrm{~A} 11, \mathrm{~A} 20$ e A22 \\
$60 \%$ & 03 & $\mathrm{~A} 19$ \\
$67 \%$ & 01 & $\mathrm{~A} 6$ \\
$73 \%$ & 01 & \\
\hline
\end{tabular}

Fonte: Os autores.

O aluno que apresentou o maior aumento percentual de acertos (73\%) após a aplicação da SD foi o aluno A6, que no pré-teste tinha acertado apenas 03 questões e no pós-teste acertou 14 (aumento de 11 acertos). Do total de alunos, nove (09) apresentaram um aumento percentual no número de acertos acima de 50\% após a aplicação da SD. Os índices intermediários, que variaram de $33 \%$ a $47 \%$, foram conseguidos por 17 alunos, enquanto os menores índices de desempenho, que variaram de $7 \%$ a $27 \%$, foram conseguidos por 12 alunos. No entanto, dentre esses alunos que tiveram desempenho menor, constatou-se que seis deles já tinham alcançado um percentual de acerto alto no pré-teste.

Apenas 03 alunos (10\%) não conseguiram melhorar seu percentual de acerto após a aplicação da SD, sendo que dois alunos (A26 e A39) 
apresentaram uma redução de $7 \%$ no percentual de acerto, correspondendo a 01 (uma) questão, enquanto o aluno A40 permaneceu com a mesma quantidade de acerto que havia conseguido no pré-teste. Apesar dos esforços em apresentar uma metodologia diversificada, sabe-se que outras variáveis podem influenciar no processo de aprendizagem.

A análise desses resultados demonstra que essa metodologia é eficaz como facilitadora do ensino e da aprendizagem de anatomia e fisiologia do sistema cardiovascular. O resultado positivo para o uso dessa metodologia também foi alcançado por diversos autores, como demonstrado na pesquisa de Borges et al. (2016), na qual realizou-se uma revisão integrativa demonstrando que tanto estes autores como os autores pesquisados por eles acreditam que a utilização de SD pode facilitar o processo ensinoaprendizagem.

\section{CONSIDERAÇÕES FINAIS}

A Sequência Didática (SD) desenvolvida apresentou grande potencial como facilitadora da aprendizagem, sendo confirmada a sua eficácia na abordagem do ensino de anatomia e fisiologia do Sistema Cardiovascular.

Em relação à problematização inicial, percebeu-se que os participantes da pesquisa já tinham certo nível de compreensão do assunto a ser abordado, mas demonstraram carências em relação à parte mais complexa do conteúdo.

Na etapa de organização do conhecimento, em relação à exposição dialogada, ficou evidenciado uma ampla participação da turma, que expressou suas dúvidas e apresentou informações que contribuíram para a construção da aprendizagem. Em relação às animações, pode-se inferir que o uso destas teve influência positiva para a aprendizagem do conteúdo de anatomia e fisiologia do SC, pois estimulou a participação dos alunos e a interatividade entre eles, que participaram ativamente e demonstraram boa compreensão ao final do trabalho. Quanto ao jogo didático, percebeu-se que essa estratégia foi eficaz como facilitadora da aprendizagem, uma vez que trouxe motivação e satisfação aos estudantes, configurando-se como 
uma ferramenta importante para a aprendizagem do conteúdo em questão.

Na etapa de aplicação do conhecimento, a prática em laboratório apresentou um cenário em que a maioria dos estudantes se envolveu de forma satisfatória, contribuindo significativamente para a aprendizagem do conteúdo. Na segunda atividade dessa etapa (reaplicação do questionário da problematização inicial) houve evolução da aprendizagem em todos os aspectos investigados, de maneira que a ocorrência de mudança conceitual ficou evidente. Os resultados referentes ao questionário pós-teste revelaram que a SD utilizada é uma metodologia eficaz como facilitadora do ensino e da aprendizagem de anatomia e fisiologia do SC.

\section{REFERÊNCIAS}

ALENCAR, E. J. et al. Sequência didática para o ensino de classificação e evolução biológica. In: $\vee$ Encontro de Iniciação à Docência da Universidade Estadual da Paraíba - UEPB. Anais... Campina Grande, PB: Realize, UEPB. 2015.

ALMEIDA, D. S. R. et al. O uso de jogos digitais como instrumento avaliativo da aprendizagem do ensino de Biologia: um relato de experiência. In: II Congresso Internacional de Educação Inclusiva. Anais... Campina Grande, PB: Realize, 2016.

ALVES, T. A. et al. Fisio Card Game: um jogo didático para o ensino da fisiologia na educação básica. Revista de Ensino de Bioquímica, v. 14, n. 1, p. 99-120, 2016.

AMABIS, J. M.; MARTHO, G. R. Biologia. 3. ed. São Paulo: Moderna, 2010.

ANASTASIOU, L.; ALVES, L. Processos de ensinagem na universidade:

pressupostos para as estratégias de trabalho em aula. 5. ed. Joinville-SC: Univille, 2005.

BALDISSERA, S. S. Ensino do sistema cardiovascular, doenças e prevenção. In: Os desafios da escola pública paranaense na perspectiva do professor PDE: produção didático-pedagógica. Cadernos PDE. Versão On-line. Vol. 2. Curitiba: SEED, 2013.

BARBOSA, A. P. L.; RAMOS, P. P; SEREIA, D. A. O uso de modelos didáticos em aulas do sistema cardiovascular. In: Os estágios supervisionados de ciências e biologia em debate II. Cascavel/PR. Anais... Cascavel/PR: Gecibio, Cascavel/PR. 2010. 
BASTOS, et al. A utilização de sequências didáticas em Biologia: revisão de artigos publicados de 2000 a 2016. In: XI Encontro Nacional de Pesquisa em Educação em Ciências, 2017. Anais... Universidade Federal de Santa Catarina, Florianópolis, SC. 2017.

BORGES, G. A.; et al. Body: um jogo digital educacional de tabuleiro na área de fisiologia humana. In: XV SBGames, 2016, São Paulo, SP. Anais... São Paulo, SP. 2016.

BRITO, V.C.; SANTOS, A. J. C. A.; OLIVEIRA, B. D. R. Análise da nomenclatura anatômica adotada nos livros de Ciências e Biologia. Revista Didática Sistêmica. Rio Grande, RS, v. 13, n. 1, p. 3-19, 2011.

CAMPOS, L. M. L.; BORTOLOTO, T. M.; FELICIO, A. K. C. A produção de jogos didáticos para o ensino de ciências e biologia: uma proposta para favorecer a aprendizagem. Caderno dos núcleos de Ensino, São Paulo-SP, v. 47, p. 4760. 2003.

CANEPPA, A. R. G. et al. Utilização de modelos didáticos no aprendizado de anatomia e fisiologia cardiovascular. Revista do Curso de Enfermagem, v.1, n.1, 2015.

DELIZOICOV, D.; ANGOTTI, J. A; PERNAMBUCO, M. M. Ensino de ciências: fundamentos e métodos. 2. ed. São Paulo: Cortez, 2002.

DIAS, C. P.; CHAGAS, I. Multimédia como recurso didático no ensino de biologia. Interações, v. 11, n. 39, p. 393-404, 2015.

DOMINGOS JÚNIOR, I. R. et al. Jogos didáticos como ferramenta pedagógica para o ensino da fisiologia humana: projeto fisiointegração. In: V CONEDU. Campina Grande, PB: Anais... Campina Grande, PB: Realize, 2018.

FELCHER, C. D. O.; FERREIRA, A. L. A.; FOLMER, V. Da pesquisa-ação à pesquisa participante: discussões a partir de uma investigação desenvolvida no facebook. Experiências em Ensino de Ciências. v. 12, n. 7, 2017.

GONÇALVES, L. J.; VEIT, E. A.; SILVEIRA, F. L. Textos, animações e vídeos para o ensino-aprendizagem de física térmica no ensino médio. Experiências em Ensino de Ciências, Cuiabá, MT, v. 1, n. 1, p. 33-42, 2006.

JESUS, L. R. de. Ensinando o Sistema Circulatório no Ensino Fundamental. 2014. 132p. Dissertação (Mestrado em Ensino de Ciências) - Universidade de São Paulo - SP, 2014.

LIMA, G.P. S.; TEIXEIRA, P. M. M. Análise de uma sequência didática de citologia baseada no movimento CTS. In: VIII Encontro Nacional de Pesquisa em Educação em Ciências, Campinas. Anais... Campinas: ABRAPEC. 2011.

LIMA, J. H. G.; SIQUEIRA, A. P. P.; COSTA, S. A utilização de aulas práticas no ensino de ciências: um desafio para os professores. Revista Técnico Científica do IFSC, Florianópolis, v. 1, n. 5, p. 86-495, 2013. 
LINHARES, S.; GEWANDSZNAJDER, F. Biologia Hoje. 2 ed. São Paulo: Ática, 2014.

LOPES, S.; ROSSO, S. Bio. 3. ed. São Paulo: Saraiva, 2017.

Manoel, J. et al. Companhia das Ciências. 4 ed. São Paulo: Saraiva, 2015.

MENDES, M. A. A. Produção e utilização de animações e vídeos no ensino de biologia celular para a primeira série do ensino médio. $103 \mathrm{f}$. Dissertação (Mestrado Profissional em Ensino de Ciências) - Universidade de Brasília, Brasília - DF, 2010.

PEDREIRA, A. J; CARNEIRO, M. H. DA S.; SILVA, D. M. S. Uso do livro didático por licenciandos em Ciências Naturais: o que me lembro e o que fiz. In: VIII Encontro Nacional de Pesquisa em Educação em Ciências, I Congresso Iberoamericano de Investigación en Enseñaza de Las Ciências. Campinas-SP. Anais... Campinas: VIII ENPEC. 2011.

PERETTI, L.; TONIN DA COSTA, G. M. Sequência Didática na Matemática. Revista de Educação do Ideau, Getúlio Vargas, RS, v. 8, n. 17, p. 1-14, 2013.

ROMANATTO, M. C. O livro didático: alcances e limites. In: VII Encontro Paulista de Matemática, Anais... São Paulo-SP, 2004.

SANT' ANNA, K. S. Diversidade metodológica como estratégia para a aprendizagem significativa de conceitos de Biologia. 74p. Dissertação (Mestrado em Ciências) - Escola de Engenharia de Lorena - Universidade de São Paulo, São Paulo-SP, 2017.

SANTOS, V. S. Anatomia Humana. 2019. Disponível em: https://brasilescola.vol.com.br/biologia/anatomia-humana.htm. Acesso em: 8 de julho de 2018.

SILVA, R. B. Ecojogo: produção de jogo didático e análise de sua contribuição para a aprendizagem em educação ambiental. 2015. 132p. Dissertação (Mestrado em Ensino de Ciências e Matemática) - Universidade Federal do Ceará, Fortaleza-CE, 2015.

SILVERTHORN, D. U. Fisiologia Humana: uma abordagem integrada. 7. ed. Porto Alegre: Artmed, 2017.

SOARES, R. M.; BAIOTTO, C. R. Aulas práticas de Biologia: suas aplicações e o contraponto desta prática. Revista Di@logus, Cruz Alta, v. 4, n. 2, p. 53-68, 2015.

WILLERS, C. D. A. et al. O processo de ensino-aprendizagem nas disciplinas de anatomia e fisiologia humana direcionado a alunos do curso de ciências biológicas. In: VIII Encontro Internacional de Produção Científica. Maringá, PR. Anais... Maringá, PR: EPCC, 2013.

ZABALA, A. A prática educativa: como ensinar. Porto Alegre: Artes Médicas, 
1998.

Recebido em: 07 de abril de 2020 Aprovado em: 01 de outubro de 2020

Publicado em: 13 de outubro de 2020

(c) (i) (8) 